\title{
O ASSÉDIO MORAL NO TRABALHO NA VISÃO DE OPERADORES DO DIREITO*
} MOBBING AT WORK ACCORDING TO OPERATORS OF THE LAW

\author{
Bruna Moraes Battistelli, Mayte Raya Amazarray e Silvia Helena Koller \\ Universidade Federal do Rio Grande do Sul, Porto Alegre, Brasil
}

\section{RESUMO}

Este estudo analisou a concepção de operadores do Direito acerca do assédio moral no trabalho, sua avaliação nas instâncias jurídicas, o perfil dos trabalhadores vitimados atendidos, assim como o papel do Direito e da Psicologia em relação ao fenômeno. Foram realizadas entrevistas semiestruturadas junto a seis operadores do Direito. Com base na análise de conteúdo das entrevistas, constatou-se uma tendência, entre os entrevistados, de perceberem a natureza organizacional do fenômeno. O medo dos trabalhadores em denunciar eventos dessa natureza foi outro elemento apontado. Os participantes afirmaram ser muito difícil avaliar e comprovar o assédio nos casos que recorrem às diferentes instâncias jurídicas. Quanto ao papel da Psicologia, os entrevistados referem sua importância para a produção de conhecimento, avaliação psicológica dos casos e prevenção da violência psicológica nas organizações. Em relação ao papel do Direito, reiteraram que as instâncias legais sejam espaços de garantia de direitos e reparação de danos.

Palavras-chave: assédio moral no trabalho; violência psicológica no trabalho; operadores do Direito; psicologia jurídica; avaliação psicológica

\begin{abstract}
This study analyses the concept of mobbing at work among operators of the Law. The assessment of this practice at legal institutions, the profile of workers affected, and the role of Law and Psychology toward this phenomenon are investigated. Six operators of the Law participated by semi-structured interviews. Based on content analysis of the interviews, it was observed a tendency to perceive the organizational nature of mobbing at work. Another element pointed by participants was the fearfulness of workers in reporting such kind of violence. The interviewed professionals also referred the hardness to assess mobbing in those cases that appeal to legal institutions. About the role of Psychology, they affirmed its importance to production of knowledge, psychological assessment of workers and prevention of psychological violence in organizations. Concerning the role of Law, they had reiterated that legal instances are spaces of guarantee of rights and repairing of damages.
\end{abstract}

Keywords: mobbing at work; psychological violence at work; operators of the Law; forensic psychology; psychological assessment.

O assédio moral no trabalho não se constitui em uma situação nova nas relações laborais. Entretanto, é nos últimos anos que alcança dimensões globais, atingindo diferentes contextos de trabalho e categorias profissionais. No Brasil, o estudo de Barreto (2003) foi um dos primeiros a enfocar o assédio moral como causa ou agravante de problemas de saúde: $42 \%$ dos 2.071 entrevistados apresentavam histórias de violência no trabalho. Em nosso país, os estudos de Amazarray (2010) e Maciel e Gonçalves (2008) também encontraram incidência elevada de assédio moral no trabalho, respectivamente $38 \%$ e $26 \%$. Nos Estados Unidos, Lutgen-Sandvik, Tracy e Alberts (2007) obtiveram prevalência de 28\%;
Mikkelsen e Einarsen (2001) relataram variações entre 8 a 25\% em amostras da Dinamarca e Noruega; na Itália, Giorgi (2008) identificou 28\% e, na Espanha, Trijueque e Gómez (2009) encontraram 14\%. As estatísticas variam bastante em função dos instrumentos utilizados, da amostra e do país. De qualquer forma, esses índices expõem a importância do fenômeno.

Diante disso, o assédio moral no trabalho vem sendo objeto de crescente preocupação mundial, por parte de trabalhadores, empregadores e também da comunidade científica. O estudo desse fenômeno é notável no âmbito da saúde, principalmente em áreas como psicologia e medicina do trabalho, devido aos danos 
físicos e psíquicos causados por esse tipo de violência. O Direito também vem se notabilizando no estudo e sistematização de conceitos e procedimentos relativos à temática, conforme apontam autores da área (Coelho, 2009; Fonseca \& Gosdal, 2009; Guedes, 2004) e artigos veiculados no site da Associação Nacional dos Magistrados do Trabalho (www.anamatra.org.br). Alguns países, como a França, já possuem legislação específica sobre a matéria (Loi n. 2002-73, 2002). No Brasil, diversas câmaras municipais e assembleias estaduais vêm aprovando leis que dispõem sobre penalidades às práticas de assédio moral no âmbito do serviço público (por exemplo, Lei Complementar n. 12.561, 2006).

O assédio moral no trabalho é um tipo de violência psicológica, caracterizado pela intencionalidade de prejudicar, pela repetição de comportamentos hostis e pela duração ao longo de um determinado tempo entre pessoas que trabalham em um mesmo contexto (Einarsen, 2000; Guedes, 2004; Leymann, 1996; Soboll, 2008). O conceito de Hirigoyen (2002, p. 17) tem sido bastante utilizado, tanto em publicações da Psicologia como do Direito:

o assédio moral no trabalho é definido como qualquer conduta abusiva (gesto, palavra, comportamento, atitude...) que atente, por sua repetição ou sistematização, contra a dignidade ou integridade psíquica ou física de uma pessoa, ameaçando seu emprego ou degradando o clima de trabalho.

Para caracterizar o assédio, deve-se levar em conta a repercussão da conduta abusiva na saúde da vítima, a periodicidade e duração do ato faltoso e a intencionalidade dos agressores (Einarsen, 2000; Freitas, Heloani \& Barreto, 2008; Leymann, 1996). Trata-se de condutas abusivas, que atentam contra a dignidade humana e podem levar os que não as suportam a adoecerem ou a tomarem decisões não esperadas quanto à vida profissional, como pedir demissão ou mudar de cargo/setor.

De acordo com Hirigoyen (2002), os comportamentos hostis podem ocorrer simultaneamente, em quatro modalidades: (a) deterioração proposital das condições de trabalho, (b) isolamento e recusa de comunicação, (c) atentado contra a dignidade e (d) violência verbal, física e sexual. Exemplificam o primeiro grupo de comportamentos práticas como: privar o acesso aos instrumentos de trabalho (telefone, computador), não transmitir informações necessárias para a realização das tarefas, atribuir serviços inferiores ou superiores às competências dos trabalhadores, ou incompatíveis com sua saúde e induzir ao erro. No segundo grupo de comportamentos hostis, encontram-se condutas como ignorar a vítima, separá-la dos outros e recusar todo tipo de contato com ela. Na terceira modalidade, podem ser utilizadas insinuações para desqualificar a vítima, espalhar rumores, fazer gestos de desprezo, desacreditá-la diante dos demais, zombar de suas qualidades físicas, origens ou nacionalidade, criticar sua vida privada, entre outros exemplos. Finalmente, no quarto grupo de comportamentos, utilizam-se ameaças de violência física ou mesmo se agride a vítima fisicamente, fala-se com ela aos gritos, invade-se a sua privacidade, assediase sexualmente, e não se leva em conta seus problemas de saúde, entre outras possibilidades.

A violência no ambiente de trabalho, na qual se inclui o assédio moral, não comporta unicamente fatores pessoais. Deve-se considerar uma combinação de fatores, como aqueles ligados aos indivíduos, ao mercado de trabalho, às condições organizacionais e às formas de interação entre os trabalhadores e seus pares, clientes e empregadores (Guimarães \& Rimoli, 2006). Einarsen (2000) identificou três formas de compreender o fenômeno: 1) a partir da personalidade de vítimas e agressores; 2) explicações baseadas nas características inerentes às relações interpessoais; 3 ) análise em virtude das características do ambiente laboral e social. Este último modelo, que enfatiza fatores organizacionais e psicossociais, tem recebido grande atenção acadêmica (Barreto, 2003; Freitas et al., 2008; Hoel \& Salin, 2003; Soboll, 2008). Segundo essa perspectiva, o assédio moral no trabalho estaria fortemente relacionado a elementos da organização do trabalho.

Recentemente, a expressão organizacional tem sido associada ao assédio para destacar que esse fenômeno pode estruturar-se a partir de estratégias de gestão do trabalho (Araújo, 2008; Hoel \& Salin, 2003; Soboll, 2008). O assédio moral organizacional teria por objetivo aumentar a produtividade e reforçar a submissão, mediante envolvimento subjetivo dos trabalhadores às regras da administração, pressionando-os à adesão aos parâmetros gerenciais e excluindo aqueles com "perfil inadequado" (Einarsen, Hoel, Zapf, \& Cooper, 2003; Schatzmam, Gosdal, Soboll, \& Eberle, 2009). Além disso, Freitas et al. (2008) destacam o assédio como um problema organizacional porque as organizações são os palcos onde essas ações ocorrem, seja por omissão ou por favorecer condições que estimulam tais práticas.

A repercussão social que o assédio moral no trabalho adquiriu, nos últimos anos, tem levado a um número cada vez maior de ações aos tribunais trabalhistas, na busca de reparação dos danos causados aos trabalhadores. Segundo Rezende (2008), essa temática perdeu o caráter inusitado, passando a fazer parte do cotidiano dos operadores do Direito. Ainda que não exista uma lei nacional que regulamente $\mathrm{o}$ assunto, tem-se utilizado a Constituição Federal e a Consolidação das Leis Trabalhistas para dar conta da reparação dos danos causados (Barros, 2004; Heloani, 2008). As convenções coletivas, conforme apontado por Barros (2004), também se constituem em um instrumento eficaz para estabelecer medidas punitivas e preventivas. 
A partir da crença de que o trabalho multidisciplinar pode ser facilitado por um mínimo entendimento entre as áreas que atuam junto a um mesmo fenômeno, propôs-se, neste estudo, uma análise da visão de operadores do Direito sobre um assunto que também diz respeito à Psicologia. Compreender o modo como operadores do Direito percebem e intervêm no fenômeno é de fundamental importância para os profissionais Psi, em especial para aqueles que atuam em Saúde dos Trabalhadores e Psicologia Jurídica. Em sua prática, esses psicólogos devem possuir um conhecimento básico sobre as instâncias legais que cercam o assunto, visando ao melhor atendimento dos trabalhadores. Nesse sentido, investigou-se o fenômeno do assédio moral no trabalho a partir da perspectiva de operadores do Direito.

\section{Método}

\section{Delineamento}

Realizou-se um estudo qualitativo, exploratório, com o objetivo de conhecer a concepção de operadores do Direito acerca do assédio moral no trabalho, a partir das instâncias legais nas quais atuam.

\section{Participantes}

Participaram do estudo seis representantes de instâncias institucionais do Direito, que atuam em Porto Alegre, procuradas pelos trabalhadores em busca de auxílio no que diz respeito aos direitos trabalhistas. Foram entrevistados uma auditora fiscal da Superintendência Regional do Trabalho e Emprego (SRTE), uma procuradora do Ministério Público do Trabalho (MPT), dois juízes do trabalho e dois advogados trabalhistas. Os participantes estavam formados há pelo menos dez anos e possuíam larga experiência profissional em suas áreas de atuação. Todos se encontravam na faixa etária dos 40 aos 60 anos. Neste estudo, os participantes serão identificados conforme o gênero e o cargo exercido (por exemplo: o advogado, a juíza).

A fim de melhor compreender as visões dos operadores do Direito entrevistados, descreve-se brevemente os objetivos das instâncias jurídicas que representam. O MPT tem como finalidade principal assegurar a observância dos direitos sociais dos trabalhadores, podendo para isso instaurar inquérito civil ou outros procedimentos, acompanhando-os e se necessário produzindo provas. A SRTE, por sua vez, visa a promover a garantia do direito ao trabalho por meio da fiscalização e orientação; apoiando a organização de novas formas de trabalho; auxiliando na mediação das relações do trabalho; da assistência ao trabalhador, entre outros. À Justiça do Trabalho compete processar e julgar as ações oriundas da relação de trabalho, abrangidos os entes de direito público externo e da administração pública direta e indireta da União, dos Estados, do Distrito Federal e dos Municípios.

A seleção dos participantes foi realizada por conveniência, utilizando-se a técnica de snowball. Inicialmente, foram entrevistadas uma procuradora do trabalho, membro do Núcleo de Proteção à Dignidade do Trabalhador do MPT, e uma auditora fiscal do trabalho, integrante do Núcleo de Igualdade no Trabalho da SRTE. Para essas duas entrevistadas, solicitaram-se indicações de advogados e juízes que atuam na área de Direito do Trabalho.

\section{Instrumentos}

Utilizou-se uma entrevista individual semiestruturada, em que os principais temas abordados foram: o entendimento de assédio moral por parte dos operadores do Direito; as técnicas utilizadas para caracterizar o fenômeno; o perfil dos trabalhadores que se apresentam às instâncias jurídicas; a possibilidade de se estabelecer nexo causal entre a doença apresentada e o assédio moral, e a percepção do papel dos psicólogos em casos de assédio moral no trabalho.

\section{Procedimentos}

O contato inicial com os participantes aconteceu por e-mail ou telefone. Nessa ocasião, explicavam-se os objetivos da pesquisa, a forma de participação e a combinação acerca do horário e local da entrevista. Essa foi realizada nos locais de trabalho dos participantes. Conforme estabelece a Resolução nº. 196/96 do Ministério de Saúde, este estudo foi submetido ao Comitê de Ética do Instituto de Psicologia da Universidade Federal do Rio Grande do Sul e aprovado sob o número 07/024. Os participantes assinaram um Termo de Consentimento Livre e Esclarecido (TCLE), no qual estavam informados os riscos da pesquisa, bem como a garantia de sigilo e confidencialidade dos dados. As entrevistas foram gravadas com permissão dos participantes, posteriormente transcritas na íntegra e submetidas à análise de conteúdo qualitativa (Bardin, 2007). Construíram-se categorias temáticas a partir das questões de entrevista e da literatura, descrevendo-as e identificando semelhanças e diferenças dos participantes em relação às mesmas. A interpretação dos resultados buscou analisar os dados trazidos pelos entrevistados à luz do referencial teórico acerca do assédio moral no trabalho.

\section{Resultados e Discussão}

A partir da análise de conteúdo, foram construídas seis categorias temáticas, apresentadas a seguir. 
Battistelli, B. M., Amazarray, M. R. \& Koller, S. H. "O assédio moral no trabalho na visão de operadores do direito"

Tabela 1

Análise das respostas dos participantes: Categorias temáticas e suas definições

\begin{tabular}{ll}
\hline \multicolumn{1}{c}{ Categoria } & \multicolumn{1}{c}{ Definição } \\
\hline Conceito de assédio moral no trabalho & $\begin{array}{l}\text { O conceito de assédio moral na visão dos operadores do } \\
\text { Direito entrevistados. }\end{array}$ \\
\hline Configuração do assédio moral por operadores do Direito & $\begin{array}{l}\text { Analisa os elementos importantes para configurar o assé- } \\
\text { dio moral no trabalho na prática de operadores do Direito. }\end{array}$ \\
\hline Trabalhadores vitimizados e instâncias jurídicas & $\begin{array}{l}\text { Apresenta um perfil dos trabalhadores vítimas de assé- } \\
\text { dio moral que buscam auxílio nas diferentes instâncias } \\
\text { jurídicas. }\end{array}$ \\
\hline Consequências à saúde & $\begin{array}{l}\text { Apresenta as consequências à saúde em decorrência do } \\
\text { assédio moral na concepção dos entrevistados. }\end{array}$ \\
\hline O papel do Direito & $\begin{array}{l}\text { Discute o papel das diferentes instâncias jurídicas repre- } \\
\text { sentadas pelos entrevistados quanto à atuação junto ao } \\
\text { assédio moral. }\end{array}$ \\
\hline O papel da Psicologia & $\begin{array}{l}\text { Refere-se ao papel atribuído à Psicologia pelos operado- } \\
\text { res do Direito entrevistados. }\end{array}$ \\
\hline
\end{tabular}

\section{Conceito de assédio moral no trabalho}

Esta categoria trata do conceito de assédio moral no trabalho trazido pelos operadores do Direito e os comportamentos que, na sua visão, configuram o fenômeno. Os entrevistados conceituaram o assédio moral de forma muito semelhante, sendo, para eles, um fenômeno que inclui diferentes tipos de pressão psicológica no ambiente de trabalho. Essa pressão traduz-se em comportamentos que atingem a dignidade dos trabalhadores, como humilhar, ofender, isolar, ridicularizar. Mencionaram que esses comportamentos devem acontecer de forma repetitiva e ao longo de um determinado período. $\mathrm{O}$ advogado salientou que o assédio moral visa à desestruturação psíquica do trabalhador, conforme expressa o depoimento: "Acho que assédio moral é uma conduta adotada pelo empregador ou por alguém, algum superior hierárquico, algum funcionário, que vise ou que provoque a desestruturação emocional desse empregado."

A intencionalidade foi outro elemento de relevância, também citado pelos demais entrevistados como sendo um fator determinante. A advogada destacou: "tem que ser deliberado, precisa ficar caracterizado que é uma conduta deliberada por parte do assediador e precisa se dar de forma repetitiva."

Em geral, as definições apresentadas pelos entrevistados corroboram a literatura. Destacaram comportamentos que atingem a dignidade dos trabalhadores de forma repetitiva, conforme indicam autores de referência na área (Barreto, 2003; Einarsen, 2000; Heloani; 2005; Hirigoyen, 2002). Embora o tempo de duração dos comportamentos seja um elemento enfatizado por alguns autores (Leymann, 1996), não foi apontado pelos entrevistados como indispensável para caracterizar o assédio. Os aspectos por eles destacados foram a repetitividade das condutas e a intencionalidade. No tocante a este último item, não se observa consenso na literatura, posto que, para alguns autores (Einarsen et al., 2003), o assédio não precisa ser necessariamente intencional, desde que sejam constatados seus efeitos de humilhação, ofensa e angústia entre os trabalhadores afetados. Ainda assim, para os entrevistados, esse parece ser um fator imprescindível na caracterização do fenômeno.

Os participantes também citaram a existência de diferentes tipos de assédio moral: o vertical e o horizontal. Segundo eles, o assédio vertical, "de cima para baixo", é o que aparece com mais frequência, no qual um superior assedia um funcionário ou um grupo de trabalhadores. Já o assédio horizontal é apontado como o tipo mais raro. A auditora fiscal do trabalho informou que essa modalidade costuma acontecer quando há, por exemplo, "um trabalhador com alguma deficiência", constituindo-se em assédio discriminatório. Por outro lado, de acordo com a advogada, "o assédio horizontal acontece em razão da hipercompetitividade, em ambientes com relações de trabalho pouco éticas". A visão dos entrevistados é corroborada pela literatura, segundo a qual o assédio vertical descendente é o mais frequente (Einarsen, 2000; Guedes, 2004). Em relação ao assédio horizontal, é interessante observar que alguns operadores do Direito já o analisam o a partir da competitividade dos ambientes laborais, como apontam alguns estudos (Hoel et al., 2001; Soboll, 2008). Essa visão possui implicações éticas e políticas importantes, na medida em que se tende a ampliar o entendimento do fenômeno, nas instâncias legais, para além das relações interpessoais, considerando também aspectos da cultura organizacional. 
A relação entre assédio moral, discriminação e humilhação nas relações de trabalho foi trazida por alguns participantes. De modo geral, os entrevistados afirmaram que essas situações, muitas vezes, confundem-se a ponto de não ser possível distinguir uma de outra. Apontaram, ainda, que são práticas inter-relacionadas e que, com frequência, ocorrem simultaneamente, como ilustra o depoimento:

Por exemplo, um empregado que retorna de um beneficio previdenciário, e se coloca ele numa sala sem equipamento com mais dois funcionários que retornaram de beneficio. Tu estás humilhando eles frente a todos os outros, porque eles vão ficar numa salinha dos incapazes, digamos assim. Tu estás praticando assédio moral, porque tu estás procurando desestruturar essas pessoas, tu estás sendo discriminatório, porque é como tu colocares todas as grávidas na mesma sala. ... tu estás discriminando numa condição de trabalho. (advogado)

Boa parte dos entrevistados mencionou a psicanalista francesa Marie-France Hirigoyen como autora de referência sobre assédio moral no trabalho. Mesmo entre aqueles que não a citaram diretamente, constatouse sua influência na forma de conceituar o fenômeno. Para Hirigoyen (2002), o assédio moral no trabalho caracteriza-se por qualquer conduta abusiva que atente, por sua repetição ou sistematização, contra a dignidade ou integridade psíquica ou física de uma pessoa. Contudo, os entrevistados não reduziram o conceito de assédio moral a tal definição, apresentando influências de outras perspectivas teóricas, como a questão da cultura nas organizações e as características do trabalho contemporâneo. Assim sendo, para os entrevistados, a organização do trabalho é central na conceitualização do assédio moral. Para os participantes, a forma de gestão no mundo do trabalho, caracterizada por competitividade, pressão por metas, sobrecarga e redução de pessoal constitui um clima propício para a ocorrência do assédio. A maioria dos participantes entendeu que o fenômeno tem origem na organização do trabalho, não se tratando de uma questão apenas individual, sendo, inclusive, política usual de algumas organizações. $\mathrm{O}$ depoimento a seguir é ilustrativo: "E essa questão do assédio moral muitas vezes não se dá só entre duas pessoas, se dá como política institucional. A instituição entende que as pessoas precisam trabalhar assim, com sobrecarga, sob pressão, é assim que elas produzem" (advogado).

O foco organizacional e social dado pelos entrevistados ao assédio moral no trabalho diferencia-se da visão mais clássica do fenômeno, que o concebe circunscrito a uma relação agressor-vítima. Essa visão tende a individualizar o fenômeno e colocá-lo no âmbito do psicopatológico, enquanto uma "perversão do ego", desconsiderando aspectos sociais. Heloani (2005) apon- ta Hirigoyen (2002) como uma das principais representantes dessa perspectiva - embora em seu segundo livro tenha relativizado o conceito e passado a considerar o papel da organização do trabalho. É contraditório que, embora os operadores do Direito tenham essa autora como referência teórica, que tende a analisar o aspecto individual do problema, também considerem a dimensão da organização do trabalho para explicar o assédio moral. Os participantes relataram que a estrutura atual de organização do trabalho, "mais compacta" (com mais trabalho e menos pessoal), não comporta espaço para trabalhadores que se encontram em desacordo ao perfil exigido pelas empresas. Assim, trabalhadores que apresentam alguma limitação na sua produtividade, como aqueles com incapacidade após licença de saúde ou aqueles que pertencem a segmentos socialmente discriminados (negros, mulheres, homossexuais etc.) estariam em situação de vulnerabilidade, sendo vítimas em potencial. O depoimento a seguir é ilustrativo:

nós podemos dizer que as pessoas que saem do padrão são as que não são homens, brancos, jovens, afirmadamente heterossexuais, de preferência casados e com filhos, sem deficiencia fisica. Qualquer pessoa que fuja deste padrão tem a possibilidade maior de ser vitima de assédio. (procuradora do trabalho)

$\mathrm{O}$ poder de mando dos empregadores e as relações autoritárias também foram apontados, com maior ou menor importância, como aspectos determinantes. Assinalaram que a relação de trabalho, envolvendo empregadores-empregados, seria desigual por definição jurídica. Segundo os entrevistados, os trabalhadores têm a crença de que os empregadores estariam em seu direito de comandar a vida dos empregados, regular suas ações, humilhar etc.

Ao referir os casos de assédio moral descendente como os mais frequentes, os participantes apresentaram a ideia de um ciclo do assédio, no qual a pressão passaria por diferentes instâncias de poder até chegar ao "chão de fábrica". A partir dessa visão, a tendência de culpabilizar gestores e gerentes pelo assédio pode ser relativizada. Faz-se necessário considerar que os gestores, apontados muitas vezes como agressores, estão também submetidos a pressões e estratégias abusivas da organização, sem autonomia para transformá-las (Soboll, 2008). Para os entrevistados, o assédio moral enquanto prática institucional deve-se, também, ao despreparo de muitos gerentes, os quais não possuem habilidades e competências para lidar com as pressões desse tipo de cargo e acabam "descontando" nos subordinados, conforme depoimento a seguir:

A questão do lucro e da competição que se estabeleceu hoje leva a esse tipo de prática, as empresas hoje não se preocupam com o que está acontecendo, mas com o resultado disso. ... Os gerentes, executivos, gestores 
destas empresas instauram este tipo de prática e ou a empresa concorda e estimula ou é omissa e não faz com que isso cesse. (juíza)

A esse respeito, para a maioria dos entrevistados, deveria haver campanhas de conscientização para empregados, orientando-lhes em relação a seus direitos e deveres do empregador. Entende-se que a visão da natureza organizacional e social do assédio moral no trabalho, apresentada pelos entrevistados, possui implicações nas suas práticas profissionais. Depreende-se que os participantes tendem a apresentar uma concepção de assédio moral no trabalho comprometida com o bem-estar e com a garantia de direitos da classe trabalhadora.

\section{Configuração do assédio moral por operadores do Direito}

Nesta categoria, são examinados os aspectos que, para os operadores do Direito entrevistados, constituemse em elementos importantes para configurar o assédio moral no trabalho. Constatou-se consenso entre eles de que a constituição da prova, item fundamental para caracterizar o assédio, é muito difícil, devido à invisibilidade e sutileza do fenômeno. Alguns comportamentos são visíveis e podem ser testemunhados, outros são muito sutis e ficam circunscritos à relação agressor-vítima ou expressam-se através de condutas discretas, como desrespeito ao trabalho, não fornecimento de materiais, ameaças, trocas de função.

Assim, para os entrevistados, a dificuldade do julgamento de ações envolvendo assédio moral no trabalho está relacionada ao problema de se constituir a prova. Para os participantes, o assédio "clássico", conforme terminologia adotada pela advogada, define-se por "condutas caricatas, como fazer alguém dançar na frente de colegas, vestir-se de mulher, entre outras", e é mais fácil de ser provado perante a Justiça do Trabalho. Entretanto, enfatizaram que, na maioria dos casos, é a prova testemunhal que possibilita a constituição de uma prova clara. Porém, explicaram que a inexistência de testemunhas é frequente, seja pela sutileza com que se dá o assédio, seja pelo receio dos colegas, que acabam não testemunhando para não colocar o seu emprego em risco - fato já documentado (Araújo, 2008; Barros, 2004; Heloani, 2008; Rezende, 2008). Incumbe à vítima apresentar os indícios que levem a uma razoável suspeita, aparência ou presunção do assédio e o demandado assume o ônus de demonstrar que a sua conduta foi razoável, que não atentou contra qualquer direito fundamental do trabalhador (Barros, 2004).

Nesse sentido, verificou-se como medida padrão entre os entrevistados o procedimento de ouvir os trabalhadores vitimados e seus colegas, investigando a ocorrência de assédio mediante avaliação da gestão do trabalho, modos de premiação, cobrança de metas etc. A juíza enfatizou que se deve fazer uma avaliação cuidadosa de todas as evidências do caso, como pode ser constatado pelo seguinte depoimento:

E nós temos que considerar essas circunstâncias especificas, normalmente a gente exige uma prova muito clara dessas ofensas morais para haver uma condenação e nestes casos parece que nós temos que fazer uma avaliação mais clara de todas as evidências. Mesmo que nós não tenhamos uma prova tão clara, nestes casos, as evidências nos levam à conclusão de que aconteceu assédio moral. (juíza)

A juíza aponta que os advogados também precisam reunir todos os indícios que contribuem para a configuração do caso perante a Justiça do Trabalho, incluindo laudos médicos e psicológicos, a fim de suprir as carências na formação dos operadores do Direito. O nexo causal, comprovação da relação entre a consequência (por exemplo, sofrimento da vítima) e sua causa (a agressão), indispensável na esfera jurídica, nem sempre é aparente, na medida em que tais humilhações são sutis (Heloani, 2005) - daí a importância dos laudos como documentos complementares. A esse respeito, o trabalho do psicólogo é fundamental para constituir o nexo causal, visto que os trabalhadores vitimados comumente apresentam sofrimento psíquico e problemas de saúde diversos decorrentes do assédio - e os operadores do Direito entrevistados parecem reconhecer a importância desse trabalho.

\section{Trabalhadores vitimizados e instâncias jurídicas}

Nesta categoria, organizou-se o conteúdo trazido pelos entrevistados referente ao perfil dos trabalhadores vítimas de assédio moral que buscam auxílio nas diferentes instâncias jurídicas. Enquanto as representantes da SRTE e do MPT atendiam diariamente muitos casos envolvendo assédio, os juízes relataram examinar poucas ações dessa natureza. Os advogados, ambos ligados a entidades sindicais, descreveram ser frequentes os casos de assédio moral que chegam ao seu conhecimento. Conforme os entrevistados, os trabalhadores vitimizados que recorrem às instâncias jurídicas costumam pertencer a segmentos sociais como mulheres, negros, homossexuais e portadores de alguma necessidade especial. Alguns dos entrevistados afirmaram que trabalhadores com estabilidade também costumam ser alvos frequentes, sendo elevados os casos de gestantes, acidentados do trabalho e representantes dos trabalhadores.

Os entrevistados citaram categorias profissionais em que as queixas aparecem com mais frequência: bancários, trabalhadores de hospitais, comerciários e teleatendentes. Em relação ao gênero, foi consenso 
entre os participantes que as mulheres procuravam auxílio jurídico com mais frequência do que os homens. Uma ressalva feita por alguns entrevistados foi de que essa constatação pode não retratar o número real de casos de assédio moral em homens e mulheres, pois há muitas situações que passam ao largo das instâncias do Direito. A esse respeito, Heloani (2005) aponta que, estatisticamente, as mulheres são as maiores vítimas de assédio moral, e também as que mais procuram ajuda médica ou psicológica. No estudo de Amazarray (2010), identificou-se que homens e mulheres estão igualmente expostos ao assédio moral; entretanto, as mulheres comumente se percebem vítimas da violência com maior frequência do que os homens. Esse fato está relacionado com a hipótese levantada pela auditora fiscal: "é mais dificil para os homens denunciarem, pois estes estariam expondo uma fragilidade individual". Nesse sentido, a advogada enfoca o preconceito por parte dos homens, que têm receio de denunciar o assédio e de procurar o serviço social/psicológico das empresas para não expor suas fragilidades. Essa afirmação é exemplificada pelo depoimento:

Tu tem que ver quem são as pessoas que chegam aqui, as mulheres procuram mais recursos, a mulher fala mais, se expressa mais, parece que o homem ... ao expor isso ele está expondo uma fragilidade dele, é mais difícil porque foi humilhado. (auditora fiscal do trabalho)

Segundo Heloani (2005), para o gênero masculino, tornar pública sua humilhação associa-se a admitir a impotência perante o ocorrido, motivo pelo qual é comum o aparecimento de sintomas psicossomáticos. A aparente passividade da vítima (em realidade, impossibilidade de defesa devido ao cerco do assédio) é vista como um atributo feminino, o que vem a agravar o quadro depressivo dos homens quando vítimas. Por outro lado, como aponta Pezé (2007), a tolerância à injustiça e ao sofrimento infligido ao outro é construída em valores viris: quanto mais se endurecem as condições de trabalho, mais as defesas se enrijecem, resultando em machismo e exacerbação das atitudes viris.

O público que procura as diferentes instâncias do Direito varia, principalmente, de acordo com a situação contratual. De acordo com os advogados e juízes entrevistados, todos os casos por eles atendidos são de trabalhadores que já saíram do emprego por não suportarem o assédio sofrido. A advogada e juíza descreveram que isso acontece pelo medo do desemprego, que faz com que muitos empregados continuem submetidos à violência nos seus locais de trabalho, tal como esclarece o depoimento a seguir:

nós temos uma particularidade aqui, nossas ações são sempre de ex-empregados, ninguém reclama no Brasil enquanto está trabalhando porque como não existe a garantia de emprego, o ingresso de uma ação no judiciário vai acabar redundando numa despedida. As ações vêm sempre depois que o contrato de trabalho já se encerrou. (juíza)

Por outro lado, as representantes da SRTE e do MPT relataram receber denúncias tanto de trabalhadores que estão empregados quanto daqueles que saíram do emprego por serem vítimas de assédio. O sigilo, no caso do MPT, foi apontado pela procuradora como favorecedor da denúncia enquanto a pessoa ainda está empregada. Além disso, deve-se considerar que a natureza dessas instituições, ligadas à fiscalização e regulação das relações de trabalho, possibilita a denúncia por parte de trabalhadores que buscam solução imediata para os conflitos. Em contrapartida, a Justiça do Trabalho comumente tem sido procurada por aqueles que visam a uma reparação dos danos sofridos.

A busca tardia pela reparação de direitos ou somente quando se dá o desemprego pode ser compreendida a partir da impossibilidade de reação da vítima, uma característica do processo abusivo de assédio moral. A insegurança no emprego incrementa as possibilidades de abuso de poder daqueles que detêm controle sobre aspectos da gestão do trabalho os quais podem afetar o bem-estar dos trabalhadores (Carou \& Serrano, 2002)1. $\mathrm{O}$ medo de perder o emprego induz tanto condutas de dominação como de submissão, sendo o assédio moral utilizado como um método de gerenciamento para desestabilizar (Araújo, 2008; Soboll, 2008). O temor de perder o emprego ou o status, de não retornar ao mercado e o medo da humilhação associam-se à competitividade e falta de solidariedade nos ambientes laborais. Esses fatores aumentam as dificuldades de defesa da vítima, podendo, ainda, associarem-se a aspectos psicológicos como baixa autoestima, gerência carismática, entre outros (Einarsen, 2000; Heloani, 2005).

\section{Consequências à saúde}

Esta categoria apresenta o que, na concepção dos entrevistados, são as consequências à saúde em decorrência do assédio moral. Portanto, as informações trazidas pelos entrevistados são parciais, visto que se referem à clientela por eles atendida e a partir do que essas vítimas relatam. Os participantes apontaram que as consequências do assédio moral para os trabalhadores podem ser as mais diversas, afetando principalmente a saúde psicológica: estresse, depressão, insônia, perda de libido, em casos mais extremos tentativa de suicídio. $\mathrm{O}$ depoimento a seguir explicita essas afirmações:

[As consequências na saúde são] as mais devastadoras possíveis, passando por insônia, alcoolismo, depressão, síndrome do pânico, vontade de não sair mais de casa, vontade de não voltar ao trabalho, afastamento 
da familia, perda de libido, pessoas que adoecem para não voltar ao trabalho. E em casos mais extremos há relatos, muitos relatos de tentativas de suicídio. (procuradora do trabalho)

Barreto (2003) identificou, em trabalhadores expostos ao assédio moral no trabalho, sintomas como crises de choro, dores generalizadas, palpitações, tremores, insônia ou sonolência excessiva, depressão, alcoolismo, diminuição da libido, ideia ou tentativa de suicídio e distúrbios digestivos. O advogado apontou o medo de voltar ao trabalho como a consequência mais forte do assédio moral, e que essa situação desencadeia outras patologias. Isso talvez possa ser explicado a partir da afirmação de Barreto (2003), ao enfatizar que o fenômeno pode ter como consequências desestruturação psicológica, perda de identidade, sentimento de inferioridade e comprometimento das relações afetivas no trabalho e na família. A dificuldade em voltar ao trabalho também pode estar relacionada ao transtorno de estresse pós-traumático, cujos sintomas de evitação, reexperimentação e ativação fisiológica foram identificados em vítimas de assédio moral (Gómez, 2006; Matthiesen \& Einarsen, 2004).

As vítimas de assédio moral não são, necessariamente, pessoas doentes ou frágeis. Pelo contrário, muitas delas tornam-se alvo do assédio justamente por não se deixarem dominar por seus superiores, tendo como característica o questionamento das ordens. Muitas vezes, é o assédio que pode vir a patologizar as vítimas, que poderão apresentar sofrimento e adoecimento a partir dessa situação (Heloani, 2005). A repetitividade e a sobreposição de diferentes agressões degradam o bem-estar e a saúde daqueles que as sofrem. $\mathrm{O}$ assédio moral é um fenômeno antigo nas relações de trabalho, mas começou a ganhar maior visibilidade e ser estudado a partir do campo da Saúde do Trabalhador devido aos impactos que provoca na saúde das vítimas (Freitas et al., 2008). A própria definição de assédio moral comporta, para muitos autores (Hirigoyen, 2002; Leymann, 1996), os impactos na saúde. Diante disso, os entrevistados parecem ter incorporado, na sua visão, que os principais prejuízos causados às vítimas são de ordem psicológica e que são efeitos das agressões sofridas. Nesse sentido, depreende-se que em suas práticas profissionais consideram essa perspectiva, tomando o cuidado de não rotular as vítimas como trabalhadores "problemáticos" e que justificariam os abusos sofridos.

\section{O papel do Direito}

Quando indagados sobre o papel do Direito junto ao assédio moral no trabalho, os entrevistados salientaram que estavam falando em nome das instituições que representam, apontando diretrizes oficiais em relação aos procedimentos que devem ser adotados. Os advogados e juízes apontaram que não existe uma posição única e definitiva da magistratura sobre o que se deve fazer diante dos casos de assédio moral. Basicamente, relataram que o papel do Direito está voltado para punição e educação. Para eles, educação e punição complementam-se, fazendo parte de uma mesma proposta. O depoimento a seguir corrobora essa função da Justiça do Trabalho, explicitada por seus representantes: "Ela deve dar o norte para que as empresas não reincidam neste tipo de conduta, para que as relações laborais se dêem baseadas no respeito à dignidade do trabalhador" (juiz).

As representantes da SRTE e do MPT enfatizaram o papel educativo dessas instâncias. Ao averiguar as situações denunciadas e propor medidas que busquem a erradicação do assédio moral no trabalho, propõem-se ações baseadas na educação. Para as entrevistadas, esse processo se dá mediante a implementação de políticas de prevenção, como cursos, palestras, ouvidorias, enfim, medidas educativas indicadas pelas instâncias jurídicas referidas.

A advogada apontou que uma das obrigações do Direito é contribuir para que o assédio moral não seja banalizado, diferenciando-o de outras situações, e "levando ao Judiciário apenas questões que realmente se configurem como assédio". Tal preocupação vem sendo objeto de diversos trabalhos (Araújo, 2008; Freitas et al., 2008; Guedes, 2004; Hirigoyen, 2002). A entrevistada indicou que os empregadores desejam a banalização do assédio para evitar a indenização e retirar seu papel na ocorrência do fenômeno. De acordo com Rezende (2008), o Direito tem se preocupado com o correto entendimento do fenômeno, a fim de evitar decisões que analisem o assunto utilizando um rigor técnico superficial. Para a auditora fiscal do trabalho, por sua vez, o Direito deve trabalhar mais voltado às questões de Direitos Humanos e atingir uma visão multidisciplinar do fenômeno. Por outro lado, conforme a juíza, o papel do Direito está relacionado à responsabilidade perante a vítima, relatando que a Justiça deve considerar o sofrimento do trabalhador. Essa perspectiva confirma o que muitos autores descrevem, como Hirigoyen (2000), ao afirmarem que acionar a Justiça é um ato difícil para aquele que sofreu o assédio, sendo uma iniciativa longa e penosa. $\mathrm{O}$ depoimento a seguir ilustra esta afirmação:

Eu acho um papel importantíssimo, porque o empregado que foi vítima de assédio moral tem como última instância para se sentir amparado de todo sofrimento, o judiciário, que no caso é o trabalhista porque é nossa competência. E se não for reconhecido judicialmente é mais uma humilhação, passar por tudo o que passou e depois ser humilhado por não ser reconhecido judicialmente (juíza) 
Assim, diante dos depoimentos dos entrevistados, pode-se constatar que consideram as instâncias legais em que atuam enquanto espaços de garantia de direitos e reparação de danos. Entretanto, também se constatou que, na sua visão, esses quesitos não estão sendo plenamente satisfeitos pelas instituições que representam.

\section{O papel da Psicologia}

Esta categoria refere-se ao papel atribuído à Psicologia pelos operadores do Direito entrevistados no tocante ao assédio moral no trabalho. Para eles, a Psicologia pode ter muitas funções: políticas de prevenção nas empresas, avaliação dos casos de assédio e produção de conhecimento para aqueles que trabalham com o tema. Para a maioria dos entrevistados, a Psicologia pode contribuir para coibir os comportamentos agressivos, mediante iniciativas que examinem as relações laborais e que permitam a escuta dos trabalhadores, de modo a que estes não sejam punidos por suas queixas, como ilustra o depoimento a seguir:

Eu acho o papel fundamental, principalmente na questão de políticas preventivas. Porque um psicólogo ele pode ser fundamental no sentido de subsidiar a empresa, no sentido propositivo, propor políticas de prevenção, código de ética e comportamento, de estabelecer relações mais fraternais, solidárias, mais civilizadas. (advogada)

Apenas o advogado apontou que a Psicologia não possui papel fundamental na questão da prova do assédio moral. O depoimento a seguir ilustra o entendimento do advogado em relação ao papel da Psicologia frente ao fenômeno: "O psicólogo pra mim, ele não é fundamental, pois eu não discuto se desestruturou ou não desestruturou a saúde mental, o que me importa é a conduta" (advogado).

O entrevistado justificou-se ao descrever que focaliza a investigação da conduta abusiva, isto é, a prova do assédio, e não as consequências deste para o trabalhador. Referiu, nesse sentido, que os psicólogos poderiam ajudar somente quando se tratasse das consequências do assédio através de laudos psicológicos. A esse respeito, os demais entrevistados também referiram a avaliação psicológica como uma contribuição para o estabelecimento do nexo causal. Para alguns entrevistados (juíza, juiz, advogada e advogado), a psicologia tem um papel importante quanto à avaliação dos danos gerados pelo assédio moral. Os laudos psicológicos foram citados como ferramentas que facilitam o entendimento dos efeitos gerados pelo fenômeno, pois, na visão desses participantes, é muito difícil para um operador do Direito investigar questões relacionadas à saúde dos trabalhadores vitimizados.

Possivelmente, as diferentes concepções sobre o papel da Psicologia diante da prova do assédio devem- se ao fato de alguns operadores do Direito enfatizarem os aspectos psicológicos, enquanto que outros destacam a "situação vexatória" e o dano à imagem que o assédio moral provoca (Barros, 2004; Heloani, 2005, 2008; Rezende, 2008). Além de contribuir mediante a avaliação psicológica, para a procuradora entrevistada, o papel da psicologia também se dá na seleção e treinamento dos cargos de chefia e gerência. Segundo a entrevistada, esta seria a medida de prevenção mais efetiva, evitando que cargos de chefia sejam designados a profissionais mal preparados. A participante afirmou que: "O psicólogo deve ter o cuidado de selecionar o mais corretamente possível, percebendo se o candidato tem os pré-requisitos exigidos para o cargo, como, por exemplo, conseguir trabalhar sob pressão" (procuradora do trabalho).

Por fim, a produção de conhecimento foi assinalada como uma das maiores contribuições que a Psicologia pode oferecer, na visão dos operadores do Direito entrevistados:

Eu acho que foi ela [Psicologia] que fez com que nós, os operadores, entendamos este processo, o que para nós é muito difícil entender toda esta questão psíquica. A psicologia tem um papel essencial no sentido de permitir que nós entendamos que isso realmente acontece e que é capaz de causar alguns tipos de doenças. (juíza)

\section{Considerações finais}

A partir deste estudo, foi possível conhecer a visão de operadores do Direito acerca do assédio moral no trabalho, a partir das instâncias legais em que atuam. $\mathrm{Na}$ visão dos entrevistados, o assédio moral refere-se a um conjunto de comportamentos que atingem, repetidamente, a dignidade dos trabalhadores, tendo por objetivo realizar pressão psicológica no ambiente laboral. Para os participantes do estudo, tais comportamentos, frequentemente, ocorrem inseridos nas políticas organizacionais, pautadas pela competitividade e estabelecimento de metas abusivas. Assim, na visão dos entrevistados, a organização do trabalho é um elemento importante para se pensar o assédio moral, apontando o medo do desemprego, por exemplo, como um fator crucial e que dificulta as denúncias por parte dos trabalhadores vitimizados. Entretanto, ressalte-se que os participantes não apresentaram um conceito único de assédio moral, cada qual salientando algum aspecto em detrimento de outro. Conforme alguns autores já referiram (Heloani, 2008; Rezende, 2008), tais concepções sinalizam a dificuldade de o Direito produzir um conceito unívoco para o assédio moral no trabalho, fato que repercute na formulação de uma legislação específica sobre o tema.

Foi consenso entre os entrevistados, no entanto, a concepção organizacional do assédio moral no trabalho. 
A partir dos depoimentos sobre suas atuações profissionais, depreende-se que essa visão do fenômeno tende a contribuir para uma compreensão crítica da violência psicológica no trabalho. Nesse sentido, tal concepção, possivelmente, tende a refletir-se em suas atuações profissionais, favorecendo práticas em prol da garantia dos direitos dos trabalhadores e da não culpabilização das vítimas - ao se evitarem perspectivas reducionistas e psicologizantes, que privilegiam a personalidade de vítimas e agressores, por exemplo. Esse dado, entretanto, deve ser examinado com cautela, visto que os operadores do Direito entrevistados constituíram um grupo reduzido de profissionais e, de certa forma, estavam vinculados a instituições que têm por finalidade justamente a defesa da classe trabalhadora. Portanto, a concepção de assédio moral apresentada pelos entrevistados não pode ser generalizada para todos os operadores do Direito.

Quanto à interlocução entre Psicologia e Direito, os entrevistados assinalaram que tal interface pode se dar na prevenção do fenômeno, junto às organizações e aos trabalhadores vitimizados, tanto antes como depois das denúncias. No que diz respeito à prova, a Psicologia teria muito a contribuir na avaliação dos casos, especificamente no estabelecimento do nexo causal entre o assédio e os transtornos psíquicos. Esse é um ponto importante e que precisa ser aprofundado, de modo a aprimorar esse tipo de avaliação e facilitar a interlocução entre as áreas.

A relação entre o Direito do Trabalho e a Psicologia ainda é pouco valorizada. Porém, este estudo demonstrou que há um grande interesse por parte dos operadores do Direito em buscar uma aproximação com outras áreas, como a Psicologia, as Ciências Sociais e a Administração. Através de uma atuação conjunta, pode-se avançar para um entendimento multidimensional do assédio moral no trabalho, com a possibilidade de intervenções interdisciplinares visando à erradicação desse tipo de violência. A partir deste estudo, destaca-se a importância da integração entre Direito e Psicologia para a melhoria da qualidade de vida dos trabalhadores.

\section{Notas}

* Este estudo teve o apoio do Programa PET Psicologia e da CAPES, mediante as bolsas de iniciação científica e de doutorado.

1 Carou, L. F. \& Serrano, C. L. (2002, novembro). Acoso moral (mobbing): Una dimensión del riesgo psicosocial. Comisiones Obreras-CCOO/Federación de Servicios y Administraciones Públicas de Cantabria-FSAP, Experiencias y actuaciones. Simposium conducted at Mobbing: El acoso laboral en el trabajo, Santander, Espanha.

\section{Referências}

Amazarray, M. R. (2010). Violência psicológica e assédio moral no trabalho enquanto expressões de estratégias de gestão. Tese de Doutorado, Psicologia, Universidade Federal do Rio Grande do Sul, Porto Alegre.

Araújo, A. R. (2008). O uso instrumental do assédio moral pelas organizações. In L. A. Soboll (Ed.), Violência psicológica no trabalho e assédio moral: pesquisas brasileiras (pp.75-92). São Paulo: Casa do Psicólogo.

Bardin, L. (2007). Análise de conteúdo. Lisboa: Edições 70.

Barreto, M. M. S. (2003). Violência, saúde e trabalho: uma jornada de humilhações. São Paulo: EDUC.

Barros, A. M. (2004). Assédio Moral. Sintese Trabalhista, 16(184), 136-155.

Coelho, L. A. T. (2009). Considerações sobre assédio moral e a prova no processo do trabalho: presunções e inversão do ônus. In T. C. Gosdal \& L. A. Soboll (Ed.), Assédio moral interpessoal e organizacional (pp.71-81). São Paulo: LTr.

Einarsen, S. (2000). Harassment and bullying at work: A review of the Scandinavian approach. Aggression and violent behavior, 5(4), 379-401.

Einarsen, S., Hoel, H., Zapf, D., \& Cooper, C. L. (2003). The concept of bullying at work. In S. Einarsen, H. Hoel, D. Zapf, \& C. L. Cooper (Eds.), Bullying and emotional abuse in the workplace (pp. 3-30). London \& New York: Taylor \& Francis.

Fonseca, R. T. M. \& Gosdal, T. C. (2009). Ministério público do trabalho e o assédio moral. In T. C. Gosdal \& L.A. Soboll (Ed.), Assédio moral interpessoal e organizacional (pp.82-93). São Paulo: LTr.

Freitas, M.E. (2007). Quem paga a conta do assédio moral no trabalho? RAE eletrônica, 6(1), 1-7. Acesso em 8 de dezembro, 2007, em http://www.rae.com.br/eletronica/index.cfm? FuseAction $=$ Artigo $\& I D=4544 \&$ Secao $=$ PENSATA\&Volume $=6 \&$ Numero $=1 \& A n o=2007$

Freitas, M. E., Heloani, R., \& Barreto, M. (2008). Assédio moral no trabalho. São Paulo: Cengage Learning.

Giorgi, G. (2008, October/December). The negative acts questionnaire revised (NAQ-R) in Italy. Prevention Today, 71-83.

Gómez, M. C. P. (2006). Manifestaciones del acoso laboral, mobbing y síntomas asociados al estrés postraumático: Estudio de caso. Psicología desde el Caribe, 17, 1-26.

Guedes, M. N. (2004). Terror psicológico no trabalho ( $2^{\mathrm{a}} \mathrm{ed}$.). São Paulo: LTr.

Guimarães, L. A. M. \& Rimoli, A. O. (2006). “Mobbing” (assédio psicológico) no trabalho: uma síndrome psicossocial multidimensional. Psicologia: Teoria e Pesquisa, 22(2), 183-192.

Heloani, J. R. (2005). Assédio moral: a dignidade violada. Aletheia, 22, 101-108.

Heloani, J. R. (2008). Contribuições da psicologia do trabalho em casos de assédio moral. In L. A. Soboll (Ed.), Violência psicológica no trabalho e assédio moral: pesquisas brasileiras (pp. 95-104). São Paulo: Casa do Psicólogo.

Hirigoyen, M. F. (2000). Assédio moral: a violência perversa no cotidiano. Rio de Janeiro: Bertrand Brasil.

Hirigoyen, M. F. (2002). Mal-estar no trabalho: redefinindo o assédio moral. Rio de Janeiro: Bertrand Brasil.

Hoel, H., Cooper, C. L., \& Faragher, B. (2001). The experience of bullying in Great Britain: The impact of organizational status. European Journal of Work and Organizational Psychology, 10(4), 443-465. 
Hoel, H. \& Salin, D. (2003). Organizational antecedents of workplace bullying. In S. Einarsen, H. Hoel, D. Zapf, \& C. L. Cooper (Eds.), Bullying and emotional abuse in the workplace: International perspectives in research and practice (pp. 202-218). London and New York: Taylor \& Francis.

Lei Complementar n. 12.561, de 12 de julho de 2006. (2006). Dispõe sobre assédio moral na administração estadual do Rio Grande do Sul. Acesso em 27 de maio, 2009, em http://www. al.rs.gov.br/Legis/Arquivos/12.561.pdf

Leymann, H. (1996). The content and development of mobbing at work. European Journal of Work and Organizational Psychology, 5(2), 165-184.

Loi n. 2002-73, du 17 janvier 2002 de modernisation sociale. (2002). Santé, Solidarité, Sécurité Sociale. (2002). Acesso em 10 de novembro, 2008, em http://www.legifrance.gouv. fr/affichTexte.do?cidTexte $=$ JORFTEXT000000408905\&fa stPos $=1 \&$ fastReqId $=2140432946 \&$ categorieLien $=$ cid\&old Action=rechTexte

Lutgen-Sandvik, P., Tracy, S. J., \& Alberts, J. K. (2007). Burned by bullying in the American workplace: Prevalence, perception, degree and impact. Journal of Management Studies, 44(6), 837-862.

Maciel, R. H. \& Gonçalves, R. C. (2008). Pesquisando o assédio moral: a questão do método e a validação do Negative Acts Questionnary (NAQ) para o Brasil. In L. A. P. Soboll (Ed.), Violência psicológica e assédio moral no trabalho: pesquisas brasileiras (pp.167-185). São Paulo: Casa do Psicólogo.

Matthiesen, S. B. \& Einarsen, S. (2004). Psychiatric distress and symptoms of PTSD among victims of bullying at work. British Journal of Guidance and Counseling, 32(3), 335-356.

Mikkelsen, E.G. \& Einarsen, S. (2001). Bullying in Danish worklife: prevalence and health correlates. European Journal of Work and Organizational Psychology, 10(4), 393-413.

Pezé, M. G. (2004). Forclusão do feminino na organização do trabalho: um assédio de gênero. Revista Produção, 14(3), 06-13.

Rezende, L. O. (2008). Revisitando os elementos estruturais do assédio moral: um caminho metodológico necessário para a correta compreensão do tema no âmbito jurídico. In L.A. Soboll (Ed.), Violência psicológica no trabalho e assédio moral: pesquisas brasileiras (pp. 57-73). São Paulo: Casa do Psicólogo.

Schatzmam, M., Gosdal, T. C., Soboll, L. A., \& Eberle, A. D. (2009). Aspectos definidores do assédio moral. In T. C. Gosdal \& L. A. P. Soboll (Eds.), Assédio moral interpessoal e organizacional: um enfoque interdisciplinar (pp. 17-32). São Paulo: LTr.

Soboll, L. A. P. (2008). Assédio moral/organizacional: uma análise da organização do trabalho. São Paulo: Casa do Psicólogo.

Trijueque, D. G. \& Gómez, J. L. G. (2009). El acoso psicológico en el lugar de trabajo: prevalencia y análisis descriptivo en una muestra multiocupacional. Psicothema, 21(2), 288-293.

Recebido em: 06/04/2009

Revisão em: 07/04/2010

Aceite final em: 21/07/2010

Bruna Moraes Battistelli é Graduanda em Psicologia pela

UFRGS. Integrante do Centro de Estudos Psicológicos sobre Meninos e Meninas de Rua (CEP-RUA) da UFRGS. Email: brunambattistelli@gmail.com

Mayte Raya Amazarray é Psicóloga, mestre em Psicologia Social e Institucional e Doutora em Psicologia pela UFRGS. Integrante do Centro de Estudos Psicológicos sobre Meninos e Meninas de Rua (CEP-RUA) da UFRGS. Docente na Universidade Federal de Ciências da Saúde de Porto Alegre (UFCSPA) e na Universidade Luterana do Brasil (ULBRA). Email: mayter@ufcspa.edu.br

Silvia Helena Koller é Psicóloga, Professora do Programa de Pós-Graduação em Psicologia da UFRGS e coordenadora do Centro de Estudos Psicológicos sobre Meninos e Meninas de Rua (CEP-RUA) desta Universidade. Endereço: UFRGS - Instituto de Psicologia. Rua Ramiro Barcelos, 2600, Sala 104. Bairro Santa Cecília. Porto Alegre/RS, Brasil. CEP 90035-003. Email: silvia.koller@gmail.com

\section{Como citar:}

Battistelli, B. M., Amazarray, M. R., \& Koller, S. H. (2011). O assédio moral no trabalho na visão de operadores do direito. Psicologia \& Sociedade, 23(1), 35-45. 